ARTIGO

\title{
O Mercosul e a Alca: os interesses (irre)conciliáveis da União Européia e dos EUA
}

\section{Introdução}

A União Européia e o Mercosul assinaram em 1995 o "AcordoQuadro Inter-Regional de Cooperação", em vigor desde 1999, que constitui um instrumento de transiçãa para a criação de um futuro acordo de associação entre os dois agrupamentos. As negociações conducentes a este acordo têm por objectivo estabelecer uma ampla parceria política e econômica, e assentam em três pilares fundamentais: diálogo político, cooperação, e comércio e investimentos. Na sua vertente comercial, visam a criação de uma zona de comércio livre. ${ }^{1} \mathrm{O}$ interesse da UE em estabelecer o acordo de associação com o Mercosul deve ser analisado atendendo ao processo de criação da Área de Livre Comércio das Américas (Alca) e aos interesses dos EUA na América Latina. Neste artigo argumentamos que a materialização da Alca e do acordo UE/Mercosul é um cenário provável no que toca aos entendimentos regionais na América

\footnotetext{
* Docente na Universidade Fernando Pessoa (Portugal). Doutor em Economia pela Universidade do Minho, Portugal.

** Professora Associada da Universidade do Minho (Portugal). Doutora em Ciência Política pela Universidade de Cincinnati, EUA (guimarmh@eeg.uminho.pt).

${ }^{1}$ A zona de comércio livre incluiria mercadorias, serviços, investimentos, contratos públicos e regras aplicáveis a domínios relacionados com o comércio como a propriedade intelectual e a concorrência, entre outros.
} 
Latina, e que a UE deve concluir as negociações com o Mercosul antes da criação da Alca. Desta forma poderá condicionar o processo conducente à formação da Área de Comércio Livre das Américas e minimizar os constrangimentos que a criação daquele agrupamento traz às relações da UE com o Mercosul.

\section{O interesse da UE no alargamento do Mercosul}

Criado pela Argentina, Brasil, Paraguai e Uruguai em 1991, com a assinatura do Tratado de Assunção no seguimento da cooperação econômica que aproximava desde 1986 o Brasil e a Argentina, o Mercosul tinha como objectivo a construção de um mercado comum. Este agrupamento tem inegável valor econômico e o seu eventual alargamento a outros países da região é do interesse da UE. Atualmente o Mercosul já representa $70 \%$ do território da América do Sul, 64\% da sua população e mais de 50\% do PIB. O espaço físico dos países do Mercosul totaliza 11.9 milhões de quilômetros quadrados, onde habitam 210 milhões de pessoas. Com um PIB superior a 1 trilhão de dólares, o Mercosul possui a principal reserva de recursos naturais do planeta e tem um potencial agrícola abundante e diversificado. É um dos mais importantes pólos de atração de investimento e em 2003 exportou cerca de 120 mil milhôes de dólares e importou mais de 88 mil milhões de dólares (FMI, 2003). A sua quota de participação no comércio mundial oscilou na década de 1990 entre $2 \%$ e $2.9 \%{ }^{2}$.

No início desta década, as exportaçōes do Mercosul (gráfico I) são destinadas fundamentalmente à UE (24\%) e aos EUA (21\%). $\mathrm{O}$ mercado europeu e estado-unidense absorvem, em percentagens muito semelhantes, cerca de 50\% das exportações do Mercosul. Estes valores traduzem o interesse do agrupamento nestes dois mercados e a importância econômica e política para o Mercosul das atuais negociações para a criação de uma área de comércio livre com a UE, bem como para a criação da Alca.

${ }^{2}$ In http://www.mercosul.gov.br/textos (CEI - Centre d'Études Interaméricaines) 


\section{Gráfico 1}

Distribuição Geográfica das Exportações do Mercosul (2000)
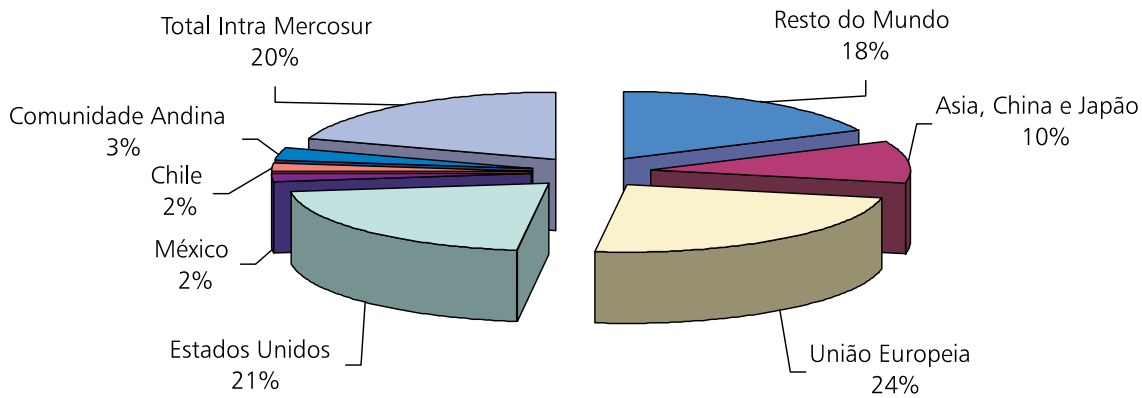

Fonte: http://www.mercosul.gov.br/textos

A criação do Mercosul provocou um grande incremento no intercâmbio comercial entre os seus Estados-membro, que se elevou de US\$ 5.1 mil milhões em 1991 para US\$ 20.5 mil milhões em 1997, quadruplicando no período de apenas sete anos. ${ }^{3}$ Em 2000, o comércio intraMercosul atingia $20 \%$ do comércio total do bloco. O aumento das trocas intra-regionais denota que a integração dos países do Mercosul potenciou o comércio de proximidade geográfica, fazendo com que este agrupamento regional se esteja a constituir como o bloco, de entre os formados por países em desenvolvimento, com maior percentagem de comércio intra-região.

Com a instituição do Mercosul pretendia-se criar um amplo espaço de livre comércio na América Latina no qual, para além dos países do Cone Sul, pudessem participar outros países latino-americanos. O Mercosul teve desde o início uma vocação subcontinental. Em 1996 assinou acordos de associação com o Chile e a Bolívia, pelos quais foi estabelecida uma área de comércio livre, a adesão desses dois países na qualidade de membros "associados", constituiu o que se passou a designar de "Mercosul político". Em 2003, o Peru torna-se também membro associado do Mercosul e desde dezembro de 2004 a Venezuela, o Equador e a Colômbia são os novos membros associados do Mercosul. Em 2004 foi firmado um Acordo de Livre Comércio entre o Mercosul

${ }^{3}$ In http://www.mercosul.gov.br/textos 
e a Comunidade Andina (CAN). ${ }^{4}$ Entretanto, em 2000, o Mercosul e o México haviam encetado negociaçôes com vista à criação de uma área de comércio livre e no início de 2004, Cuba apresenta um pedido formal de acordo comercial com o Mercosul.

Esta dinâmica de formação de acordos económicos com os países da região pode ser interpretada como um passo prévio para o alargamento do Mercosul, o qual passaria a ter um peso econômico e político na região deveras significativo. A criação do Mercosul e a celebração desses acordos constituem estratégia, liderada pelas duas maiores economias do subcontinente (Brasil e Argentina), para fortalecer o agrupamento e conseqüentemente para diminuir a vulnerabilidade das economias da região à hegemonia político-econômica dos EUA. Por outro lado, esta estratégia, ao incrementar as relações económicas externas do bloco, permite aumentar a capacidade negocial do Mercosul com a União Européia na criação do acordo de associação UE/Mercosul, e com os EUA na criação da Alca.

Um eventual alargamento do Mercosul serve os interesses da UE. Os fortes laços históricos e culturais entre os países dos dois lados do Atlântico, que levaram à existência de grandes colônias de emigrantes europeus, especialmente portugueses, espanhóis e alemães, são em grande parte responsáveis pela existência de significativos fluxos comerciais e de investimento da UE para o Mercosul. Esses fluxos, no entendimento da UE devem não só ser preservados, mas ampliados, e o alargamento do Mercosul propicia tal objetivo.

Para os EUA, pelo contrário, a ampliação do Mercosul, não serve os seus interesses na região, pois reforça o poder negocial dos países do Mercosul no processo de criação da Alca, reduzindo os benefícios económicos e políticos que os EUA esperam retirar deste agrupamento.

\section{Alca: vantagens dos EUA com a integração assimétrica}

Os interesses norte-americanos na América Latina assumem, desde há muito, particular relevância. Trata-se de uma região que os EUA se

${ }^{4}$ À Comunidade Andina pertencem o Chile, a Bolívia, a Colômbia, o Equador, o Peru e a Venezuela. 
habituaram a considerar de sua influência natural e onde durante várias décadas exerceram a sua supremacia econômica, política e militar. ${ }^{5}$

Em 1990, quando os EUA se centravam nas negociações do Nafta, o então presidente norte-americano George Bush lançou a proposta "Iniciativa para as Américas", que assinalaria o retomar da doutrina Monroe de 1823, que estabelecia que a América Latina era uma área de influência dos EUA. Com esta proposta, os EUA procuravam evitar que outra potência econômica, nomeadamente a União Européia, adquirisse papel de relevo na América Latina.

No seguimento da "Iniciativa para as Américas", teve lugar a "Cimeira das Américas" em 1994, na qual os presidentes de 34 países formalizaram a proposta de criação de uma Área de Comércio Livre das Américas em 2005, com o objetivo de, entre outros aspectos, eliminar as tarifas para a generalidade do comércio entre os membros, estabelecer normas para regular o comércio de bens e serviços, os investimentos, as compras governamentais, a propriedade intelectual e a agricultura.

Morais (2000), refere que o projecto de integração hemisférica constitui uma adaptação do estilo de intervencionismo norte-americano na região ao novo contexto internacional e uma nova forma dos EUA ampliarem a sua influência na América Latina, numa recriação da aludida doutrina Monroe. Com a aceitação, na década de 1980, dos processos de regionalismo, os EUA iniciam também uma política de integração econômica com a América Latina, onde até então a sua intervenção política havia encontrado resistência. Os EUA recorrem agora a um novo instrumento - a integração econômica - para prosseguir a velha doutrina Monroe.

Segundo alguns autores, o pedido de concessão de fast track $k^{6}$ do presidente Bill Clinton para negociar o acordo Nafta, já tinha implícito a sua ampliação a toda a América Latina. Por outro lado, na negociação do Nafta, a aceitação, com limitadas exigências por parte dos EUA, das

\footnotetext{
5 São exemplos as intervenções no Panamá (1914), Haiti (1915), República Dominicana (1916), Nicarágua (1925-1933) e o apoio dado a muitas das ditaduras políticas que favoreciam os interesses econômicos dos EUA, de que o Chile de Pinochet constitui exemplo paradigmático ${ }^{6} \mathrm{O}$ pedido de fast track é uma solicitação feita ao Congresso pelo presidente dos EUA para poder negociar acordos comerciais sem ter de aguardar a decisão do Congresso, geralmente demorada.
} 
condições pretendidas pelo México, o país não desenvolvido daquele bloco comercial, indicia a intenção dos EUA de virem a negociar a expansão do Nafta a outros países com um nível de desenvolvimento econômico semelhante ao do México. Assim, os EUA pretendem que o Nafta se torne num modelo de integração a ser expandido a outros países da América Latina, em particular ao Brasil.

Embora a administração americana sustente que a Alca a liberalização do comércio e do investimento, para a generalidade dos países latinoamericanos a criação da Alca é uma resposta ao interesse das grandes empresas dos EUA em acederem a novos mercados. A debilidade econômica e a necessidade de acesso ao grande mercado norte-americano, constrangem os países latino-americanos, com a excepção do Brasil, de questionar abertamente os objectivos da Alca. Conforme assinala Simões (2002), a forte assimetria entre os países é uma das características mais evidentes do processo Alca e um dos maiores desafios na construção da sua política de coesão económica e social. Os EUA respondem por cerca de 77\% do PIB dos países que constituiriam a Alca; o PIB dos EUA e Canadá em conjunto eleva-se a $82 \%$; à América Latina cabem apenas $18 \%$, dos quais $10 \%$ correspondem aos países do Mercosul. Os restantes 25 países apenas representam 8\% do PIB. A Alca configura assim um empreendimento de grande complexidade, dada a disparidade de desenvolvimento das economias envolvidas.

Jaguaribe (2001) refere que nas negociações da Alca a eliminação das barreiras aduaneiras proposta pelos EUA representa um muito maior esforço de liberalização para os países do Mercosul do que para os EUA - no Mercosul essas barreiras são da ordem dos 13\%, enquanto que as tarifas dos EUA são já muito baixas (cerca de 3\%). Por outro lado, os EUA propóem-se salvaguardar o seu direito de impor barreiras não tarifárias unilateralmente, como sejam os direitos anti-dumping, protecções fitossanitárias, quotas, para além de outras restrições à entrada, que poderão prejudicar fortemente os países latino-americanos, particularmente os do Mercosul.

Prevendo a habitual pressão dos lobbies norte-americanos em caso de conflito de interesses, o acordo tenderá a proporcionar melhores condições de concorrência às empresas dos EUA. Atente-se no poderoso grupo de pressão agrícola norte-americano e pode antecipar-se que os 
produtos agrícolas da América Latina e designadamente do Mercosul, terão muita dificuldade em penetrar no mercado dos EUA. Tem pois, de ser sublinhado que a integração na Alca, seja do Mercosul, seja de cada um dos países latino-americanos isoladamente, envolve uma situação desigual nas condições de concorrência. Simões (2002) chama a atenção para o fato de, em termos objetivos, os EUA considerarem que esta negociação comercial hemisférica lhes é francamente favorável. Em primeiro lugar, porque o peso da economia norte-americana garante uma enorme vantagem comparativa na negociação das regras do futuro tratado. Em segundo lugar, a maior competitividade da economia dos EUA facilita o aumento das exportaçóes norte-americanas para a América Latina, a área que registou o maior crescimento das exportaçóes dos EUA durante a década passada (300\% entre 1990 e 1997). ${ }^{7}$

Morais (2000a) assinala que o projecto Alca ao integrar economias de tamanho e nível de desenvolvimento assimétrico, torna previsível que não seja fácil conciliar os diferentes interesses nacionais. Assim, muitos países da América Latina advogam que a liberalização comercial deve ser precedida por estágios intermédios de abertura, de natureza sub-regional e regional, de forma a minorar os custos de transição, a assegurar a diversificação de parceiros comerciais e a garantir o tratamento não discriminatório dos investimentos extra-hemisféricos no cenário após 2005.

Contrariando os que antecipam vantagens para a América Latina decorrentes do esperado acréscimo de Investimento Direto Estrangeiro (IDE) vindo dos EUA, Jaguaribe (1998) lembra que é improcedente a tese de que a criação da Alca atrairá grandes investimentos americanos para a região: com o derrube das barreiras aduaneiras, deixará de existir estímulo para realizar investimentos na região, pois as empresas americanas podendo vender sem sobrecarga aduaneira, já não necessitam de deslocalizar as produções. A evidência demonstra que, entre outras motivações, o que atrai o IDE é a existência de grandes mercados com proteção aduaneira e o tratamento favorável desses investimentos sob a forma de incentivos fiscais e outros, como acontece atualmente nos países do Mercosul. Se a Alca vier a se constituir, essas barreiras aduaneiras serão

\footnotetext{
${ }^{7}$ As importaçōes norte-americanas provenientes do Mercosul aumentaram apenas 23\%.
} 
eliminadas, deixando de ser atrativo para as empresas norte-americanas investir na região.

A formação da Alca é, pois, um instrumento fundamental para os EUA acentuarem a sua influência na América Latina e para condicionarem quer o papel do Mercosul na região, quer o seu alargamento; no limite a Alca poderá mesmo levar à extinção do Mercosul.

\section{A resistência do Brasil às negociações da Alca}

O processo de integração econômica dos EUA e da América Latina tem sido travado pelo Brasil. O Brasil pretende afirmar-se como uma grande economia regional e até mundial, e receia a integração num espaço integrado ao qual pertence a economia americana. Os EUA, sabendo desta pretensão (que tem vindo a ser expressa pelo anterior e pelo atual presidente do Brasil), e reconhecendo as potencialidades da economia brasileira, consideram fulcral a participação deste país na Alca. Estudos do Banco Mundial, bem como projeçōes do governo brasileiro (Calderón, 1998), indicam que o Brasil terá no futuro uma participação no produto mundial que poderá alcançar 2,5\% em 2020 (e que era de $1,5 \%$ em 1992). Nos próximos dez anos o Brasil vai ser um dos dez países responsáveis por $40 \%$ do comércio mundial, pelo que os EUA têm todo o interesse em que o mercado brasileiro seja rapidamente aberto às suas empresas. O Brasil não possui qualquer acordo preferencial com os EUA, razão pela qual a integração do mercado brasileiro na Alca se torna ainda mais atraente para as empresas americanas. Acresce que o Brasil tem crescente poder político na região, por força da sua preponderância no Mercosul e da sua ação com vista ao alargamento do agrupamento. Os esforços do Brasil na criação e ampliação do Mercosul constituem prova das suas capacidades e aspiraçōes. Do espaço $4+6$ países, ${ }^{8}$ o Brasil é considerado como o mais independente na sua política externa e como o país com maiores possibilidades de desempenhar um papel de relevo no sistema econômico internacional. Esse papel preocupa os EUA. Aos EUA não convém que o maior país da região ascenda à categoria de

\footnotetext{
${ }^{8}$ A expressão 4+6 pretende traduzir os acordos dos quatro países do Mercosul (Brasil, Argentina, Uruguai, Paraguai) com os seis países associados (Chile e Bolívia, em 1996, Peru em 2003 e Venezuela, Equador, Colômbia, em 2004).
} 
potência econômica, que lidere um agrupamento regional alargado capaz de concorrer com os EUA e que, como refere Roett (1998), possa vir a influenciar o Mercosul no sentido de privilegiar um relacionamento com a União Européia em detrimento da Alca.

Para o Brasil, a adesão a Alca, apesar da plétora de ressalvas não tarifárias, não é uma opção economicamente atrativa. Como sintetiza Jaguaribe (2001), a Alca é uma forma de os EUA penetrarem no mercado brasileiro. O Brasil não necessita da Alca para entrar no mercado americano - mesmo sem a adesão a Alca, os produtos de alto valor acrescentado que o Brasil exporta para os EUA continuarão a sê-lo, porque não são produzidos pelos restantes países sul-americanos. Ao Brasil convém o fortalecimento do Mercosul, pois tal permite-lhe ter maior poder nas negociaçôes da Alca. Esse poder negocial poderá também ser reforçado se o Mercosul estabelecer o acordo de associação com a UE. Saliente-se que do ponto de vista do Mercosul as negociaçôes com vista à formação da Alca não excluem uma aproximação à UE, podendo até motivar uma mais forte aproximação. Ora nenhuma destas situações é do interesse dos EUA.

A UE pode retirar vantagens dos interesses divergentes dos EUA e do Brasil na negociação da Alca, tendo em vista a afirmação e a salvaguarda dos seus interesses na região. Para tal deve procurar acelerar o processo de criação do acordo de associação com o Mercosul.

\section{UE/Mercosul: potencialidades nas relações econômicas e dificuldades negociais}

As trocas comerciais entre a UE e a América Latina têm aumentado desde o início da última década - totalizavam cerca 29 mil milhões de euros em 1990, aumentaram para 66 milhões de euros em 1996 e atingiam 104 mil milhôes de euros em 2000. ${ }^{9}$ Os bens com maior peso nas exportações da UE para a América Latina são as máquinas e o material de transporte (52\%), enquanto que os bens que a UE mais importa da América Latina são produtos agrícolas (38\%), seguidos a grande distância pelas máquinas $(9 \%)$.

\footnotetext{
${ }^{9}$ In Eurostat (http://www.europa.eu.int/comm/trade/goods/states.htm)
} 
Das exportações da UE com destino à América Latina, 50\% têm como destino o Mercosul ${ }^{10}$ e este é também na América Latina o primeiro fornecedor da UE. As trocas UE/Mercosul aumentaram significativamente nos anos 90, com um crescimento de mais de 100\% entre 1990 e 2001. Este crescimento deveu-se principalmente às exportações da UE para o Mercosul, as quais aumentaram 302\%; as exportaçôes do Mercosul para a UE cresceram $60 \%$.

\section{Quadro 1}

Trocas comerciais UE/Mercosul (1990-2001, em milhões de US\$)

\begin{tabular}{|l|c|c|c|c|c|c|}
\hline & 1990 & 1992 & 1994 & 1996 & 1998 & 2001 \\
\hline Exportações da UE para o Mercosul & 5.848 & 8.664 & 15.703 & 21.928 & 26.456 & 23.520 \\
Exportações do Mercosul para a UE & 14.450 & 15.310 & 16.743 & 18.090 & 20.072 & 23.128 \\
\hline
\end{tabular}

Fontes: Pareja, 2001 e http://europa.eu.int/comm/world/lac/merc.htm

O aumento das exportações da União Européia com destino ao Mercosul, deveu-se em grande medida ao interesse das empresas européias pelos mercados daquela região, o qual levou em 1998 à criação do Fórum de Negócios Mercosul/UE, destinado a promover a liberalização do comércio e do investimento. Das vendas da União Européia para o Mercosul 95\% são produtos industriais.

A UE é o principal parceiro comercial do Mercosul e como refere Silva (2002) "ocupa tradicionalmente um lugar destacado no comércio destes países (...), o que tem de resto implicações profundas que ultrapassam o mero horizonte comercial". Com referência a 2001, 24\% das exportaçóes do Mercosul tiveram como destino a UE. Das vendas do Mercosul para UE, 50\% são produtos agrícolas (51\% provenientes da Argentina, 25\% do Brasil e 42\% do Uruguai), sendo a UE o maior comprador de produtos alimentares do Mercosul. Segundo Grandi (1999) o Mercosul é a quarta potência alimentar mundial e o terceiro fornecedor de produtos agrícolas da UE. Esta capacidade de produção e de exportação de bens agrícolas a preços competitivos constitui preocupação para o setor agrícola francês, subsidiado pela

${ }^{10}$ Surge em segundo lugar a Comunidade Andina com 19\%. 
PAC, e explica os entraves que a França tem colocado ao aceleramento das negociações entre a UE e o Mercosul para a criação de uma área de comércio livre. Das importações de produtos industriais provenientes do Mercosul, 53\% são já isentas de direitos aduaneiros e os restantes $47 \%$ estão, desde 2001, a ser gradualmente liberalizados, ao longo de dez anos, sendo que em 2008 grande parte dessas importações já não estará sujeita a direitos aduaneiros.

No que respeita ao IDE, a União Européia é o segundo maior investidor na América Latina, a seguir aos EUA e muito à frente do Japão. $\mathrm{O}$ volume do investimento direto europeu nunca teve a expressão que tem hoje. Perante o êxito dos planos de estabilização econômica dos países da América Latina, as alteraçôes na conjuntura mundial e os programas nacionais de privatização, criaram-se condições de confiança para os investimentos europeus na região. A Comissão Européia (1999) refere ainda que para além das afinidades históricas, culturais e linguísticas, as principais causas destes tais fluxos financeiros são a ampla participação de capitais europeus nos processos de privatização de empresas públicas latino-americanas, e também a forte presença de bancos europeus nos programas de conversão da dívida. Cerca de 60\% do IDE europeu na América Latina teve como destino o Mercosul, especialmente a Argentina e o Brasil. Nos últimos anos assistiu-se a uma crescente concentração nestes dois países, os quais em 1999 foram, juntamente com o Chile, destinatários de cerca de $90 \%$ do investimento direto europeu na América Latina.

Quadro 2

Distribuição do IDE dos Estados-Membro da UE na América Latina (1995-2000, em \%)

\begin{tabular}{|c|c|c|c|c|c|c|c|}
\hline Espanha & Reino Unido & Portugal & Alemanha & França & Países Baixos & Itália & Outros EU \\
\hline 44 & 13 & 11 & 10 & 8 & 7 & 2 & 5 \\
\hline
\end{tabular}

Fonte: Cepal (2001)

A Espanha, cujos investimentos já se evidenciavam desde 1993, voltou a ocupar no período $1995-2000$ a primeira posição, agora mais destacada, com 44\% de todo o IDE da União Européia na América Latina 
(quadro 2). Seguiam-se os investimentos do Reino Unido e Portugal, com apenas $13 \%$ e $11 \%$ respectivamente ${ }^{11}$ e só depois a Alemanha.

Segundo dados da Cepal (2001) relativos a 1996-1997, os setores de atividade mais procurados pelos investidores europeus foram a "electricidade, gás e água" (23\%), o "financeiro" (10\%) e o "comércio" (7\%). Segundo a mesma fonte, das dez empresas multinacionais com maior volume de vendas na América Latina em 2000, sete foram empresas européias. ${ }^{12}$ No que respeita à percentagem das vendas de empresas comunitárias para aquela região sobressaem duas empresas ibéricas: a "Portugal Telecom", com 63.5\% das suas vendas na América Latina e a “Telefónica España”, com $56.7 \%,{ }^{13}$ Estas percentagens refletem a aposta destas empresas no mercado latino-americano, e explicam em grande medida o interesse dos países ibéricos num relacionamento mais estreito e de caráter formal com o Mercosul.

O IDE europeu no Mercosul tem tido um aumento muito significativo: em 1999 totalizaram 29.455 milhões de dólares contra apenas 1.147 em 1992 (quadro 3), o que representa um aumento de $2.468 \%$.

\section{Quadro 3}

Investimentos da UE no Mercosul (1992-2000, em milhões de dólares)

\begin{tabular}{|c|c|c|c|c|c|c|c|c|}
\hline 1992 & 1993 & 1994 & 1995 & 1996 & 1997 & 1998 & 1999 & 2000 \\
\hline 1.147 & 1.105 & 2.172 & 2.267 & 6.217 & 8.238 & 24.033 & 29.455 & 23.176 \\
\hline
\end{tabular}

Fonte: Cepal (2001)

Segundo o CESE (2001), nos últimos anos esses investimentos têm desempenhado um papel cada vez mais relevante nas relaçóes econômicas

\footnotetext{
${ }^{11}$ No caso de Portugal, dada a reduzida dimensão econômica do país, este valor é um fluxo financeiro muito forte para aqueles mercados. Várias empresas portuguesas aproveitaram as privatizaçōes de alguns setores de atividade brasileiros para crescerem, já que o mercado português não oferecia condições de expansão, decisão que foi facilitada pela existência de laços culturais e linguísticos que ligam Portugal ao Brasil.

12 Destaca-se a Espanha ( $1^{\circ}$ e $6^{\circ}$ lugar), Alemanha ( $3^{\circ}$ e $\left.4^{\circ}\right)$, França (5), Itália $\left(8^{\circ}\right)$ e Países Baixos $\left(10^{\circ}\right)$.

13 A empresa que ocupa a posição cimeira em volume de negócios, entre todas as empresas com IDE na América Latina é a Telefónica España. Em 2000 as suas vendas totalizaram 41 mil milhôes de dólares, o que corresponde a mais de treze vezes as vendas efetuadas pela empresa americana "The Coca-Cola Co", que ocupa a 2a posição em volume de vendas na mesma região e no mesmo ano.
} 
entre a UE e o Mercosul. A opção dos investidores comunitários pelo Mercosul explica-se em parte pelas expectativas que têm nas negociações para a criação de uma área de comércio livre UE/Mercosul, a qual aumentará a segurança e potenciará a rentabilidade dos seus investimentos nas economias do Mercosul. Entre os países receptores de tais investimentos sobressaíram, como já se aludiu, o Brasil e a Argentina. No Brasil, o IDE passou de 89 milhões de dólares em 1991 para 33 mil milhōes de dólares em 2000, embora com tendência para baixar, por terem sido já privatizadas as suas maiores empresas. A Espanha figura em primeiro lugar de entre os países da UE que mais investiram no Brasil no período 1992-2000, com 23 mil milhões de dólares, seguida de Portugal com cerca de 9 mil milhóes de dólares. No caso da Argentina, o montante do IDE, foi de 2.5 mil milhões de dólares em 1991, e elevou-se para mais de 11 mil milhões em 2000. A Espanha foi também o maior investidor na Argentina no período 1992-2000, sendo responsável por 49\% do total do investimento comunitário naquele país.

Portugal e Espanha, no momento de adesão a então CEE, em 1986, tinham um papel diminuto nas relações econômicas e de cooperação e desenvolvimento com os países do atual Mercosul, especialmente pelo fato de outros países já deterem importantes posições na região, como era o caso da Alemanha (Freres, 2000). A adesão de Espanha e de Portugal deu um forte impulso às relaçôes econômicas com o Mercosul. Com efeito, tanto Portugal como Espanha passaram a realizar investimentos vultosos naquela região, no que foram acompanhados por outros Estadosmembro. Simultaneamente também as transações comerciais com os países da região registaram um acréscimo. A partir de então a UE passa a valorizar mais as relaçôes econômicas com o Mercosul, e estes dois países em particular procuram assegurar a defesa dos seus interesses na região, nomeadamente incentivando a criação de uma zona de comércio livre com o Mercosul.

O importante fluxo de investimentos comunitários no Mercosul e a expressividade das trocas comerciais entre os dois agrupamentos justifica um relacionamento formal entre os dois parceiros econômicos. Se por um lado, para os países do Mercosul um acordo de livre comércio pode potenciar ainda mais as relações econômicas com a União Européia, esta poderá retirar grandes benefícios com o estabelecimento desse 
acordo, nomeadamente intensificando os fluxos de investimento e as trocas comerciais. As relações econômicas da UE com o Mercosul e os esforços para as enquadrar num acordo formal, denotam que a Europa comunitária tem um papel a desempenhar naquela região, e que os interesses da UE e dos EUA estão aí em concorrência, pondo em causa a percepção dos EUA de que a América Latina constitui uma área de sua influência natural.

\section{As dificuldades negociais}

As relações formais entre a Europa Comunitária e os países da América Latina iniciaram-se pouco tempo após a entrada em vigor do Tratado de Roma em 1958, tendo os então seis Estados-membro da CEE entendido promover e desenvolver as relaçôes comerciais e econômicas com os países daquela região. Nos anos 60 a CEE apoiou também os processos de integração regional latino-americanos e na década de 1980 celebrou acordos de cooperação com a generalidade dos agrupamentos regionais da região, designadamente com o Mercado Comum Centro Americano, com o Pacto Andino e com a Associação Latino-Americana de Desenvolvimento e Integração. Nos anos 90 manteve um diálogo permanente com o Mercosul, tendo os dois agrupamentos, em 1992 (menos de um ano após a criação do Mercosul), assinado um Acordo de Cooperação Interinstitucional. Sete anos depois, em 1999, entra em vigor o Acordo-Quadro Inter-Regional de Cooperação, pensado para fazer a transição para um futuro acordo de associação UE/Mercosul, que formalizaria uma aliança estratégica de natureza econômica e política entre regióes com interesses complementares.

No entanto, a UE não tem conseguido imprimir o dinamismo e a celeridade que se impunha ao processo negocial com o Mercosul, ${ }^{14}$ o que contrasta com a importância econômica do Mercosul para UE e com a premência política de estabelecer um acordo de associação. De fato, as negociações já tiveram início em novembro de 1999, e já se realizaram 16 ciclos negociais, não tendo ainda terminado. ${ }^{15} \mathrm{O}$ último ciclo ocorreu

\footnotetext{
${ }^{14}$ Sobre o processo negocial UE/Mercosul veja-se Bouzas (2004).

${ }^{15}$ Em 2000 ocorreram dois ciclos negociais, em 2001 três, em 2002 dois, em 2003 três e em 2004, cinco ciclos.
} 
em outubro de 2004, tendo os dois blocos estabelecido que a nova reunião ministerial deveria ocorrer no primeiro trimestre de 2005. As conclusôes de cada um dos ciclos negociais, com especial incidência nos mais recentes, dão a entender que o acordo está eminente para o ciclo seguinte; no entanto, uma vez este iniciado, verifica-se reiteradamente que são retomados temas sobre os quais parecia já ter sido alcançado um entendimento. No último ciclo negocial, não ficou mesmo estabelecido o prazo para a conclusão das negociações.

A principal causa para este moroso processo negocial de aprofundamento e formalização das relações entre a UE e Mercosul reside nas questões relativas ao setor agrícola. A Política Agrícola Comum (PAC) tem constituído um dos maiores obstáculos ao estabelecimento de um acordo de associação com o Mercosul. Já no Fórum EuroLatino-Americano de $1998^{16}$, vários intervenientes alertavam para as implicaçôes da PAC nas negociaçôes e para as suas consequências em um relacionamento formal com o Mercosul. Mais recentemente e apesar da celeridade que se tem procurado imprimir ao processo negocial, as dificuldades relacionadas com a PAC travam esse dinamismo. A PAC para além de não cumprir as regras do Gatt/OMC, prejudica particularmente os interesses dos países do Mercosul, cujas vantagens comparativas no mercado europeu se situam em grande medida nos produtos agrícolas e agropecuários. Com os subsídios que concede aos agricultores comunitários, a PAC torna os preços dos produtos agrícolas europeus artificialmente mais baixos no mercado interno, dificultando a exportação de produtos agrícolas do Mercosul para a UE. Como nota, Martins (2000), a persistência de uma estratégia proteccionista por parte da UE em torno da sua "sacrossanta" política agrícola é um dos maiores erros estratégicos da política européia, tal como comprovam os entraves que cria ao estreitamento das relações com o Mercosul. ${ }^{17}$

\footnotetext{
16 Relatório do Fórum Euro-Latino-Americano (1998) denominado "Uma parceria para o século XXI".

${ }^{17}$ Trein (2001) refere as principais dificuldades que a PAC introduz nas negociaçóes: elevada autosuficiência do mercado intracomunitário em produtos agrícolas; barreiras tarifárias e não tarifárias por parte da UE; quotas e subsídios à produção; concorrência por parte dos países signatários do Acordo de Lomé/Cotonu aos produtos do Mercosul no mercado comunitário; e alteraçóes no Sistema de Preferências Generalizadas (SPG) destinado aos países em desenvolvimento.
} 
Segundo Dâmaso (2000), no debate interno da UE sobre as vantagens e as desvantagens de um acordo UE/Mercosul, de um lado estão os países com fortes interesses agrícolas, como a França, que têm dificultado este processo, e do outro, estão países como a Alemanha que percepciona a reforma da PAC como condição essencial para a efetivação de um acordo com o Mercosul. A divergência de interesses agrícolas e industriais nas negociações comerciais entre a UE e o Mercosul não facilitou nem a criação de uma agenda nem a sua negociação, apesar de ambos os agrupamentos concordarem que um acordo de associação trará benefícios para ambas as partes. É aceitável que na negociação de um acordo de comércio livre se reconheçam as sensibilidades especiais de alguns setores europeus, que não podem expor-se de maneira imediata à concorrência global, sobretudo o setor agrícola, como recorda Klaveren (2000). O que não é aceitável, segundo o autor, é a morosidade imposta pelo setor agrícola, que tem uma política que necessita de ser revista com urgência para evitar consequências eventualmente irreparáveis nas relaçôes UE/Mercosul.

A abertura gradual do mercado europeu aos produtos agrícolas do Mercosul, além de poder contribuir para uma maior eficiência na utilização dos recursos agrícolas comunitários, possibilitaria maior abertura do mercado sul-americano a um maior número de produtos europeus e a mais investimentos da UE, o que poderia compensar, em parte, os custos associados à reforma da PAC.

A França, como principal beneficiária dos subsídios da política agrícola, é o país que coloca mais dificuldades à reforma da PAC e indiretamente trava a formalização de um acordo UE/Mercosul. É de alguma forma contraditório e até irônico que a França persista na sua recusa de reformar a PAC e esteja a inviabilizar o acordo da UE com o Mercosul e a dar espaço negocial aos EUA, seu concorrente no sistema internacional, para criar a Alca. Ao fazê-lo a França está a prejudicar os interesses comunitários no subcontinente americano e a criar condições para um aumento da preponderância dos EUA na região, algo que a França exatamente não pretende. 


\section{A Alca na equação negocial UE/Mercosul}

A formalização de um acordo de associação entre a UE e o Mercosul não é um processo independente da criação da Alca. As negociações para a constituição da Alca colocam à União Européia a necessidade urgente de acelerar e concluir as negociações com o Mercosul, de forma a salvaguardar os seus interesses naquela região e a condicionar os esforços dos EUA para criar a Alca. O Comité Económico e Social Europeu (2001) alerta para o fato de a Alca constituir um repto para a União Européia, que vai além do âmbito econômico, pois a formação de uma zona de comércio livre hemisférica conduzirá a um reforço da influência política dos EUA na região.

$\mathrm{O}$ acordo UE/Mercosul representa a melhor oportunidade de a UE reforçar as relaçôes econômicas e políticas com a América Latina, pelo que não é de seu interesse que o Mercosul se dilua na Alca. De acordo com alguns autores, os maiores benefícios para a UE da relação mais estreita com o Mercosul resultam da sua dimensão estratégica (Fórum, 1998). Para prosseguir estes objetivos estratégicos a UE tem que oferecer ao Mercosul condições para potenciar o comércio e assim criar as bases para uma relação politicamente mais estreita.

O interesse da UE num acordo de associação com o Mercosul e a crescente interdependência econômica entre os dois agrupamentos, não é do agrado dos EUA, que receiam ver diminuída a sua influência naquela região; não apenas a influência política, mas em especial a econômica, o que poderia significar a perda de quotas de mercado. Se a tal se adicionar o facto de o Mercosul, desde a sua constituição em 1991 até ao lançamento do projeto Alca em 1994, ter aumentado o seu comércio intra-região (de cerca de 10 mil milhões de dólares para aproximadamente 24.5 mil milhões, consolidando-se enquanto espaço comercial integrado) e ter reforçado o volume das trocas com o exterior, compreende-se o interesse dos EUA na celeridade da conclusão do processo negocial conducente à Alca. Segundo o Relatório do Fórum Euro-Latino-Americano (1998) a criação de tal super-bloco é uma peça da estratégia americana de afirmação da sua predominância política e comercial global, e uma forma de os EUA neutralizarem o Mercosul, e limitarem a capacidade do Brasil para questionar a sua afirmação político-económica na América Latina. Ora 
estas são as razões que devem levar a UE a acelerar as negociações para o Acordo de Associação com o Mercosul. Segundo Valladão (1998), só uma estreita cooperação entre a Europa e a América Latina pode garantir a diversidade e especificidade destes dois blocos face ao "rolo compressor norte-americano".

Por outro lado, ao procurar evoluir para um Mercado Comum, o Mercosul acrescenta um elemento positivo para o reforço da associação com a UE. O bloco regional para onde a UE canaliza uma parte significativa do seu comércio e investimento direto estaria mais consolidado, o que estimularia as trocas e os investimentos entre a União Européia e o Mercosul. Por sua vez, com o Mercosul já constituído em Mercado Comum, os países da América Latina que tiverem acordos preferenciais com aquele agrupamento, poderão se beneficiar do acordo de associação do Mercosul com a UE e verão a sua posição face EUA mais fortalecida e menos vulnerável. Finalmente, para o Mercosul seria mais benéfico o estabelecimento de uma zona de comércio livre com a UE do que a pertença à Alca (CESE, 2001). Sem um acordo UE/Mercosul antes de concluídas as negociaçóes da Alca, o Mercosul corre o risco de, a prazo, vir a desaparecer, o que não interessa nem aos países que integram o agrupamento nem à UE, mas conviria aos EUA.

\section{Cenários possíveis e interesses (irre)conciliáveis da UE e EUA}

São quatro os possíveis cenários de evolução dos entendimentos regionais na América Latina. O quadro 4 esquematiza esses cenários e identifica quer a possibilidade da sua ocorrência quer o interesse da UE e dos EUA na sua materialização.

\section{Quadro 4}

\begin{tabular}{|l|c|c|c|c|c|c|}
\hline & Alca & Mercosul & Acordo UE/Mercosul & $\begin{array}{c}\text { Possibilidade } \\
\text { de ocorrência }\end{array}$ & Interesse UE & Interesse EUA \\
\hline Cenário 1 & não & $\operatorname{sim}$ & $\operatorname{sim}$ & -- & ++ & -- \\
Cenário 2 & $\operatorname{sim}$ & $\operatorname{sim}$ & não & + & - & - \\
Cenário 3 & $\operatorname{sim}$ & não & não & - & -- & ++ \\
Cenário 4 & $\operatorname{sim}$ & $\operatorname{sim}$ & $\operatorname{sim}$ & ++ & + & + \\
\hline
\end{tabular}


O primeiro cenário, muito pouco provável, supõe a inexistência da Alca e a efetivação de um acordo de livre comércio UE/Mercosul. Este cenário é o que mais interessa à União Européia, visto dar boas garantias para os investimentos comunitários atuais e futuros na região, assim como para o incremento das trocas entre os dois agrupamentos regionais. Este cenário não interessa aos EUA, pois significaria que o processo Alca não se teria concretizado, e que pelo contrário o Acordo UE/Mercosul seria alcançado.

No segundo cenário supõe-se a existência da Alca e a manutenção do Mercosul, mas não se tendo materializado o acordo UE/Mercosul. A situação é provável, mas não do interesse da União Européia, nem dos EUA. Nesta hipótese tanto as trocas como os investimentos comunitários destinados aos países do Mercosul (e também à restante América Latina) seriam significativamente reduzidos. A constituição de um superbloco comercial, integrando as principais economias da América Latina na esfera da economia dos EUA, conduziria ao estabelecimento de um amplo espaço com regulamentações e práticas comerciais homogéneas, definidas sob influência dos interesses dos norte-americanos e poderia erigir uma barreira comercial aos produtos oriundos da União Européia. Para os EUA este é um cenário com algum interesse, pois a não assinatura do Acordo UE/Mercosul seria uma vitória relativa dos EUA. No entanto, a manutenção do Mercosul não permitiria maximizar os interesses dos EUA na região, pois teria dentro da Alca um bloco regional que poderia condicionar a sua influência econômica, e até política, na região.

Um terceiro cenário pressupóe o desaparecimento do Mercosul após a constituição da Alca e conseqüentemente inviabilização do Acordo UE/Mercosul. É um cenário cuja possibilidade de ocorrência é reduzida e que não é do interesse da União Européia, mas que seria o que mais vantagens proporcionaria aos EUA - as relações preferenciais entre o Mercosul e a UE não se materializariam e a extinção do Mercosul evitaria os condicionalismos que este bloco poderia impor sobre o desenvolvimento do processo de integração da Alca. O poder dos EUA na região sairia reforçado, mas também no sistema internacional e nas instituiçóes internacionais, nas quais passariam a contar com o apoio de mais 33 países. 
O último cenário admite a existência da Alca e do Mercosul e de um Acordo de Associação UE/Mercosul. Esta hipótese é a que tem mais possibilidade de vir a ocorrer. É um cenário que interessa à União Européia - embora não maximize os seus interesses - porque salvaguarda os investimentos comunitários naquela região e possibilita o crescimento do fluxo de trocas entre os dois agrupamentos. Para os EUA é um cenário que não sendo ótimo, satisfaz em grande medida os seus interesses embora o Mercosul continue a existir e se efetive o acordo de associação UE/Mercosul, a Alca logra constituir-se.

Face aos interesses económicos da UE no Mercosul e tendo em conta as ambiçōes econômicas e políticas dos EUA na América Latina, a estratégia reactiva aos avanços da Alca que a UE tem adaptado, não é favorável à defesa dos seus interesses na região. É nosso entendimento que uma estratégia proactiva e menos defensiva face aos progressos na criação da Alca seria mais vantajosa para a UE. Assim, a União Européia deveria valorizar mais a premência de um acordo de associação com o Mercosul e apostar na aceleração das negociações a ele conducentes, antecipandose à formação da Alca, de forma a salvaguardar os seus interesses na região e a condicionar o processo negocial da área de comércio livre do hemisfério americano.

Recebido em 27 de maio de 2005 Aprovado em 29 de junho de 2005

\section{Referências Bibliográficas}

BOUZAS, Roberto. Mercosur's experience of preparing trade negotiations with the EU. A Memorandum. CEDPREM, Discussion Paper no 50, 2004.

CALDERÓN, Álvaro. Competitividade Internacional e Desenvolvimento das Regiōes. Debates. S. Paulo, Brasil, Fundação Konrad-Adenauer-Stiftung, no $15,1998$.

CEPAL. Unión Europea: Inversiones y Estratégias Empresariales en América Latina y el Caribe. Http://www.eclac.cl/cgi-bin/get/getProd.asp?xml/publicaciones, 2001. (10.4.2003). 
CESE. Parecer sobre as negociaçôes entre a União Européia e o Mercosul e o Chile: aspectos económicos e sociais. Comité Econômico e Social Europeu. Bruxelas, CÊS 932/2001.

COMISSÃO EUROPÉIA. Relações Econômicas e Comerciais. União Européia América Latina, Avançando Juntos. Luxemburgo, junho 1999.

DÂMASO, Joana. O Futuro das Relações entre a UE e o Mercosul. O Mundo em Português. IEEI, Ano I, no 4, janeiro 2000.

FMI (Fundo Monetário International). Financial Statistics Yearbook 2003. 2003.

FÓRUM Euro-Latino-Americano. A União Européia e o Mercosul: uma nova Relação? Uma parceria para o século XXI, Regularizar e Democratizar o Sistema Mundial. Relatório (versão preliminar). Lisboa, 21-22 maio 1998.

FRERES, Christian. Las Relaciones Interregionales Unión Europea-América Latina: Del Predominio de lo Político al Económico. VI Forum Euro-LatinoAmericano. Lisboa, 25-26 fevereiro, 2000.

GRANDI, Jorge e SCHUTT, Daniel. Bilan de Sept Années de Mercosur. Problèmes d'Amérique Latine. La Documentation Française, no 322 Janvier-Mars 1999.

JAGUARIBE, Hélio. O Mercosul e as alternativas para a ordem mundial. Fórum Euro-Latino-Americano. Lisboa, 21-22 maio 1998.

JAGUARIBE, Hélio. A Alca e o Mercosul. O Mundo em Português. IEEI, ano II, número 19, abril 2001.

KLAVEREN, Alberto Van. Chile, el Mercosur y la Unión Europea. VI Forum Euro-Latino-Americano. Lisboa, 25-26 Fevereiro, 2000.

MARTINS, Vítor. Integração Regional, Multilateralismo e Globalização. VI Fórum Euro-Latino-Americano. Lisboa, 25-26 fevereiro 2000.

MORAIS, Paulo. Alca: a hesitante integração hemisférica. O Mundo em Português. IEE, ano 1, no 4, janeiro 2000.

MORAIS, Paulo. A Área de Livre Comércio das Américas numa Perspectiva do Mercosul. Fórum Euro-Latino Americano. Working Paper 7, abril 2000a.

PAREJA, Enrique. América Latina/União Européia: por um futuro melhor. Elo: Cooperação e Desenvolvimento, no $34 \mathrm{dez} / \mathrm{jan} 2001$.

ROETT, Riordan. A União Européia e o Mercosul: as perspectivas dos Estados Unidos. Fórum Euro-Latino-Americano. Lisboa, 21-22 maio 1998. 
SILVA, Joaquim Ramos. Portugal/Brasil: uma década de expansão das relaçôes económicas, 1992-2002. Lisboa: Terramar Editores, 2002.

SIMÕES, António J. F. A Alca no Limiar do Século XXI: Brasil e EUA na Negociação Comercial Hemisférica. Instituto para a Integração da América Latina e do Caribe (INTAL). Documento de Trabalho 9. Buenos Aires, maio 2002.

TREIN, Franklin. A Agenda Européia da Próxima Década: suas consequências para as relaçôes com o Mercosul. $4^{\text {th }}$ International Workshop on European Economy. CEDIN/ISEG/Lisboa, 25 e 26 maio 2001.

VALLADĀO, Alfredo. Estados Unidos - Europa - América-Latina. Ângulo, Triângulo ou Polígono? Fórum Euro-Latino-Americano, Lisboa 21-22 maio 1998.

\section{Resumo}

Os interesses dos EUA na América Latina e a criação da Alca são fatores determinantes para explicar o propósito da União Européia de estabelecer um Acordo de Associação com o Mercosul. Enquanto que à UE interessa o alargamento do Mercosul, os EUA preferem, por meio da criação da Alça, induzir a sua dissolução e retirar vantagens da integração assimétrica. O nosso objetivo é demonstrar que, face aos cenários possíveis de evolução dos entendimentos regionais na América Latina, o mais plausível (co-existência do Mercosul, do Acordo de Associação UE/Mercosul, e da Alca) é também aquele que permite reconciliar os interesses da UE e dos EUA na região.

\section{Abstract}

The interests of the United States in Latin America and the creation of the FTAA are two determinant factors in explaining the European Union intention to establish an Association Agreement with Mercosur. While the European Union is interested in the Mercosur enlargement, the US prefer, through the creation of the FTAA, to induce its dissolution and obtain advantages from asymmetric integration. Our purpose is to demonstrate that, given the possible scenarios of evolution in regional agreements in Latin America, the most plausible (co-existence of Mercosur, EU/Mercosur Association Agreement and FTAA) is also the one that allows for a reconciliation of EU and US interests in the region.

Palavras-chave: Mercosul, Alca, União Européia, Comércio, Investimento. Key words: MERCOSUR, FTAA, European Union, Trade, Investment. 